\title{
ESTUDIO DEL RUIDO GENERADO POR LA MAQUINARIA DE CONSTRUCCIÓN EN INFRAESTRUCTURA VIAL URBANA
}

\section{Samuel Huaquisto Cáceres e Isabel Griscelda Chambilla Flores}

\section{RESUMEN}

El ruido generado durante el proceso constructivo de las infraestructuras viales urbanas es uno de los problemas ambientales que inciden negativamente en la calidad de vida de los trabajadores y de la población aledaña. Este estudio tiene el propósito de analizar los diferentes niveles de presión sonora generados por la maquinaria de construcción en vías urbanas con pavimento rígido. Los niveles de ruido monitoreados han sido realizados al equipo mecánico pesado y liviano en proceso de operación. Los resultados globales indican rangos de niveles de presión sonora que van desde 69.6 dBA a 98.4 dBA, siendo los equipos mecánicos livianos los más influyentes con dosis que exceden el 100\%. La etapa más ruidosa es la del corte de concreto en pavimento que presenta un nivel de presión sonora de 89.12 dBA en la tarea con dosis que excede en más del $100 \%$, en las demás tareas no hay excedencia de los valores críticos estipulados para una jornada laboral de 8 horas de trabajo; sin embargo, influyen en la población adyacente debido a que exceden los 60 dBA para zona residencial en horario diurno. En conclusión, el equipo mecánico utilizado en la construcción de vías de concreto emite niveles de presión sonora superiores a los límites permisibles incidiendo en la población y trabajadores, recomendándose el uso de protectores auditivos de un nivel mínimo NRR 19 dB para operadores de equipo mecánico pesado y NRR $35 \mathrm{~dB}$ para equipos livianos.

Palabras Clave: Decibel, Maquinaria, Presión Sonora, Ruido, Sonómetro.

DOI: 10.23881/idupbo.021.1-7i 